LINDNER - HÖRN UND VERSTEHEN 
SAMMLUNG AKADEMIE-VERLAG

40

SPRACHE 


\section{GERHART LINDNER}

\section{HOREN \\ UND VERSTEHEN}

Phonetische Grundlagen

der auditiven Lautsprachperzeption

Mit 29 Abbildungen im Text

AKADEMIE-VERLAG - BERLIN

1977 
Erschienen im Akademie - Verlag, 108 Berlin, Leipziger Straße 3-4 (C) Akademie-Verlag Berlin, 1977 Lizenznummer : $202 \cdot 100 / 181 / 77$

Herstellung: IV/2/14 VEB Druckerei «Gottfried Wilhelm Leibniz*, 445 Gräfenhainichen 4870

Bestellnummer : $7522084(7540) \cdot$ LS V 0805

Printed in GDR

DDR 15,- M 